\title{
Educação básica no Brasil: a agenda da modernidade
}

\section{SIMON SCHWARTZMAN}

A

modernidade morreu; viva a pós-modernidade! É esta a palavra de ordem que ecoa no Brasil, oriunda principalmente dos círculos literários, e invade com força as ciências sociais, a historiografia, e agora a educação. Na perspectiva pós-moderna, o mundo já teria superado os tempos do Iluminismo, e com eles a crença no poder da razão, nas promessas do futuro e na valorizaçáo da ética do trabalho e do desempenho. A razão, desenvolvida nas ciências e transmitida pelos sistemas escolares, ter-se-ia revelado uma forma disfarçada de exercício do poder, e, além de tudo, incapaz de apreender a verdadeira natureza das coisas; a tecnologia, sua filha bastarda, estaria destruindo o meio ambiente, prostituindo a mente pelos mass media e ameaçando de destruiçăo a própria humanidade. $O$ futuro, que o Iluminismo apresentava como inteligível em suas leis e conquistável pelo trabalho, agora se apresentaria como incerto e sombrio. Náo só o capitalismo agonizaria, mas também seu alterego, o socialismo. Se a razão aliena e o futuro inexiste, e se Deus já foi há muito declarado morto, tampouco faria sentido fixar metas na vida, postergar desejos, perseverar.

Partindo destas premissas, é natural que o Pós-Modernismo não se constitua como uma visão coerente e organizada do mundo. Sua preeminência nos meios literários não é fortuita: rechaçando o conhecimento racional e abstrato, ele tende a se apoiar, sobretudo, na intuiçáo e na capacidade de expressão simbólica dos artistas. Não que faltem, evidentemente, seus teóricos, responsáveis pelo desenvolvimento de críticas profundas e muito pertinentes à crise de sentido e de valores que perpassa as sociedades modernas. Mas, uma vez terminada a tarefa crítica e iconoclasta, e destruída a legitimidade da atividade racional(1), o espaço se abre para autores geralmente obscuros em sua linguagem, pródigos de formulaçóes categóricas e de difícil compreensão, fundando, freqüentemente, movimentos e escolas nos quais só se penetra pela via da iniciação. É uma tarefa inglória, por isto, tentar descrever o que seja o Pós-Modernismo, e que alternativas propóe para o mundo da modernidade(2). É possível, no entanto, tentar o caminho inverso, ou seja, tratar de examinar em que medida a modernidade, como vertente contemporânea do Iluminismo, ainda se mantém como valor e como 
caracterização da época contemporânea, e mais especificamente, como a questáo da modernidade se coloca no Brasil de hoje, e particularmente no que nos interessa mais de perto no momento, que é o da educação básica nacional.

O conceito de modernizagfio foi introduzido pelas ciências sociais no período de pós-guerra para caracterizar os processos de transição que os países e naçóes atrasados, ou subdesenvolvidos, deveriam, esperava-se, passar para alcançar os níveis de renda, educaçáo e produtividade tecnológica característicos dos países industrializados. A modernizaçáo dos países industrializados ter-se-ia dado antes, pelo desenvolvimento da produção industrial, pela substituição das formas de conhecimento tradicionais pela ciência e tecnologia de base experimental, pela organizaçáo de um estado burocrático e pela introduçáo de novas formas de relacionamento social baseadas no contrato e na reciprocidade de interesses, e náo mais na tradiçáo ou no carisma - tudo, em uma palavra, que Max Weber descreveria com o termo racionalização. Autores mais conservadores viam nos processos de modernização um caminho harmônico de superação progressiva de etapas, enquanto que outros, mais radicais, preferiam o evolucionismo histórico conflitivo e dialético do marxismo.

O termo modernização começou a entrar em desgraça quando ficou claro que nem todos os países e sociedades seguiam os mesmos passos através da história, e quando as esperanças de um progresso contínuo das ex-colônias e países periféricos aos níveis e padrões de desenvolvimento dos países mais ricos começaram a se desfazer. Modernidade surge entáo como um termo muito mais geral e amplo. Ele não traz as conotaçóes evolucionistas e de convergência do anterior, mas sugere que todas as sociedades, hoje, compartem um destino e uma condiçáo similar, descrita como uma grande proximidade com as novas tecnologias e, ao mesmo tempo, uma grande incerteza, instabilidade e desencantamento com um mundo onde, na frase de Marx recuperada por Berman, " tudo que é sólido desmancha no ar" (3).

A criação de instituições capazes de produzir conhecimentos científicos e produtos tecnológicos e a difusão desta competência em toda a sociedade são certamente um privilégio daquelas sociedades que já conseguiram se modernizar e racionalizar de forma mais abrangente, no sentido weberiano do termo. No entanto, o uso de produtos tecnológicos altamente sofisticados, como automóveis e videocassetes; a adoçáo de alguns tipos de indústrias modernas baseadas em equipamentos sofisticados dotados de um grande componente tecnológico desencarnado e manejado por uma mão-de-obra pouco qualificada; o uso de armas 
modernas e sofisticadas; a adoção de estruturas administrativas e gerenciais capazes de operar com bastante eficiência os meios de comunicaçáo de massas, de coleta e de organizaçáo de informaçōes, parecem estar hoje totalmente generalizados. $O$ que caracteriza a modernidade, nesta perspectiva, náo é o conhecimento e o comando destas tecnologias, que é privilégio de poucos, mas a convivência e a exposição a elas, das quais ninguém escapa. A estas características, que poderíamos chamar de estruturais, se somam outras de tipo valorativo, ou normativo: existe a expectativa de que as sociedades modernas sejam democráticas, que garantam as liberdades individuais, $\mathrm{e}$ que proporcionem a seus cidadăos segurança, educação e bem-estar.

O otimismo ingênuo do Iluminismo e do Modernismo, em suas diferentes versóes, tem sido atacado desde seus primórdios tanto pelo pensamento conservador quanto pelas formas mais radicais de crítica, do marxismo à psicanálise, assim como pelo assalto da literatura, das artes, de Baudelaire a Charles Chaplin. E no entanto, os dilemas trazidos pela condiçáo de modernidade estão cada vez mais presentes e são cada vez mais fundamentais no mundo de hoje, substituindo, possivelmente, a polarização de classes explicitada por Marx e que, segundo Sartre teria dito um dia, definiria a condiçáo existencial central do mundo contemporâneo. Ser moderno, no mundo de hoje, é poder conviver de forma adequada com os instrumentos da racionalidade em todos seus aspectos - na produção econômica, na organizaçáo política, na organização do espaço físico, na previsibilidade da vida e no planejamento do futuro. "Conviver de forma adequada" significa incorporar estes instrumentos, colocá-los a serviço do bem-estar de todos, e não se deixar seduzir, dominar e destruir por eles. Se isto faz algum sentido, então os Estados Unidos não seriam tão modernos quanto a Europa ou o Japão, por exemplo; mas a China seria infinitamente mais moderna do que a Índia. A pergunta importante para as ciências sociais de hoje é a das condiçóes de emergência desta nova modernidade, das estruturas e visōes de mundo que a obstaculizam, e das que a viabilizam. É possível que, na busca de respostas a esta pergunta central, possamos chegar à visão global de uma nova modernidade, livre dos pressupostos evolucionistas e cientificistas do passado, e capaz, inclusive, de recuperar a tradiçăo humanística que as ciências sociais mais "duras" foram deixando de lado. Nada impede que esta "nova"abordagem se denomine, por exemplo, de "pós-moderna" (4); mas o discurso da "pós-modernidade" que hoje predomina é, quase sempre, uma tentativa de evadir estas questóes, $\mathrm{e}$ por isto não me parece aceitável.

\section{A redescoberta da questão educacional}


Recolocar em primeiro plano a questão da modernidade significa, em grande parte, trazer a questão educacional para o centro das preocupaçốes. A redescoberta e revalorização da questáo educacional é hoje um tema candente, e uma das tarefas mais centrais das ciências sociais contemporâneas. No passado não muito distante, temas como o da escola pública persus escola particular, a educaçáo religiosa, ou direito à educação em língua materna mobilizavam sociedades inteiras, enchiam os jornais e decidiam os resultados de eleições. A educaçáo pública, universal e gratuita foi uma das grandes bandeiras do pensamento republicano a partir da Revolução Francesa, e a defesa do ensino privado e de base familiar, sustentada pelas autoridades e pensadores católicos, marcou e marca até hoje os debates do tema. Na sociologia de Émile Durkheim a educaçáo era vista não somente como uma necessidade instrumental das sociedades modernas, mas como o único cimento que poderia efetivamente mantê-la integrada e solidária. $O$ tema da renovaçăo educacional fascinava os intelectuais russos nos primeiros anos da Revolução de Outubro, e seria retomado nas preocupaçóes de Gramsci.

Nas últimas décadas, no entanto, a questão educacional como que desapareceu como tema intelectual, transformando-se em assunto meramente técnico ou administrativo. Esta desqualificação teve como conseqüência que os temas relativos à educação saíssem do foco dos grandes debates e discussóes, ficando como que relegados aos especialistas, e entregues ao conflito localizado de interesses das partes mais diretamente envolvidas com as instituições educacionais: pais, professores, secretarias e ministérios de Educação, livreiros, funcionários. A relativa decadência do tema da educaçáo básica se explica, em parte, pela progressiva expansão das universidades e do ensino superior nas últimas décadas, atraindo para si os melhores talentos $\mathrm{e}$ as principais atençóes, e relegando o ensino básico para setores sociais menos privilegiados e menos capazes, conseqüentemente, de trazer seus temas e interesses para o foco das atençóes. A isto se somou a difusáo da idéia de que, como fenômeno superestrutural, a educação em si pouco podia fazer para alterar as condiçóes de vida ou o sistema de poder de uma sociedade, cujas molas mestras estariam na política e na economia(5). Esta desqualificaçăo da tarefa educacional tornou-se ainda mais acentuada a partir da difusão dos trabalhos de Bourdieu e Passeron, que procuravam demonstrar como os sistemas educacionais simplesmente reproduziam as estruturas de dominaçáo existentes na sociedade mais ampla. Uma vez introduzidas entre os educadores, estas idéias se somaram às suas frustraçōes com a falta de apoio, prestígio e reconhecimento de que eram vítimas, levando ao abandono quase definitivo das preocupaçōes de natureza pedagógica, substituídas seja pela militância política, seja pela apatia pura e 
simples.

A redescoberta da educação se relaciona com a constatação de que, longe de serem neutras, as instituiçóes educacionais têm um impacto bastante significativo, ainda que controverso, sobre as sociedades contemporâneas. Por um lado, análises econômicas complexas se somam à observação quotidiana na demonstração de como a educação, como capital humano, tem uma contribuição decisiva para a criaçáo da riqueza e para o desenvolvimento econômico. É cada vez mais claro, por exemplo, o papel central que a educação jogou na ascensão do Japáo como potência econômica de primeira grandeza nas últimas décadas, que parecè estar se repetindo com igual força em outros países asiáticos de industrialização recente, como a Coréia do Sul e Taiwan; é também bastante clara, e dramática, a limitação que a ausência de uma populaçăo educada coloca para um país como o Brasil, no momento em que o desenvolvimento da automação industrial coloca em risco uma de suas principais pantagens comparativas internacionais, que era a existência de mão-deobra abundante, desqualificada e barata. Por outro lado, estudos sobre o impacto dos sistemas educacionais sobre a estratificaçáo social mostram que, ao contrário das expectativas otimistas do passado, estes sistemas tendem frequientemente a consolidar e acentuar a desigualdade social; esta perspectiva tem sido especialmente salientada após a frustração das esperanças depositadas, nos Estados Unidos, nos programas de afáio afirmativa nas escolas como forma de reduzir as desigualdades raciais que afetam a população negra naquele país. A conciliação destes dois pontos de vista, em si mesmo verdadeiros, requer uma visão mais complexa a respeito do relacionamento entre instituiçóes educacionais e as de tipo econômico e social. Assim, quando uma sociedade se expande, a educaçáo parece funcionar como instrumento poderoso de mobilidade social de novos grupos, e de incorporaçáo de novas tecnologias e conhecimentos à sociedade; quando as sociedades estão estagnadas, a educação parece funcionar, sobretudo, como elemento de seleção e discriminação social. Sozinha, ela pode menos do que se acreditava no passado; em conjunto com outros processos de natureza social, política e econômica, a educaçăo pode marcar a diferença entre o sucesso e o fracasso.

\section{Itens de uma agenda}

Além destas análises de tipo global, esta redescoberta tem sido acompanhada de uma grande ampliação no escopo do que tradicionalmente se considerava como o campo da pedagogia, que hoje inclui desde consideraçōes institucionais e organizacionais até análises linguiísticas, culturais e motivacionais. Esta ampliação está levando a uma nova agen- 
da de questóes, algumas das quais vale a pena ressaltar aqui.

Hoje se constata, por toda parte, o fracasso das tentativas de se valer da educação formal como mero mecanismo de transmissão de ideologias convencionais, tal como se tentou, no Brasil, com a tristemente famosa Educafáo Moral e Cívica; ao mesmo tempo, no entanto, as experiências de associar a educação com a motivaçáo política e social, reintroduzidas pela chamada "pedagogia do oprimido" de Paulo Freire, não só mostraram que a educação retém seu potencial político e ideológico, como que a existência de um componente motivacional forte joga um papel fundamental na própria transmissão dos conteúdos educacionais mais tradicionais, a capacidade de ler, escrever e contar. Esta aparente contradição se explica pelo fato de que a educação não é um mero procedimento técnico e neutro, capaz de transmitir igualmente bem qualquer tipo de conteúdo. Se ela responder a uma motivação e a um interesse do educando, e se esta motivação e interesse forem estimulados, ela será bem aceita; caso contrário, ela será, inevitavelmente, rechaçada (6).

A redescoberta da motivação como elemento fundamental nos processos educativos coloca em segundo plano certos temas e faz ressaltar outros. Ela permite questionar, por exemplo, as tentativas de explicar os fracassos educacionais de crianças de famílias deprivadas por fatores lingüísticos ou culturais. Filhos de imigrantes não são menos capazes de apreender os conteúdos lingüísticos e culturais dos países de adoção de suas famílias, e o fazem, muitas vezes, bem melhor do que os nativos. A proposta de associar o ensino básico a variaçôes lingüísticas regionais e sub-regionais, além de equivocada como forma de compensar eventuais problemas de motivação, se choca com a globalização dos padróes de linguagem promovidos pelos meios de comunicaçáo de massas, e resultaria, se fosse bem sucedida, na acentuação do isolamento e marginalidade social dos grupos sociais menos privilegiados. Perdem saliência, também, as antigas querelas pedagógicas que opunham diferentes técnicas de ensino da leitura ou maneiras de introduzir conceitos numéricos. Ainda que estas questóes continuem sendo importantes (pensemos, por exemplo, no desastre pedagógico que tem sido a introdução da nova matemática ou da substituição da história e da geografia pelos chamados estudos sociais nas escolas secundárias), uma criança motivada em um ambiente estimulante adquirirá seus conhecimentos básicos por qualquer método, mesmo os mais tradicionais e arcaicos, ou os mais moderninhos e avançados.

O mesmo raciocínio se aplica aos entusiasmos, hoje bem mais reduzidos, com as chamadas novas tecnologias educacionais, das calcu- 
ladoras de mão à televisão e ao computador. Utilizados de forma competente e por professores experimentados e motivados, estes instrumentos podem tornar as aulas mais interessantes e sugestivas; pouco podem, no entanto, como substitutos eventuais dos professores e de instalaçóes escolares adequadas. Também caiu rapidamente em descrédito a noçáo de que, ao aprender a programar um microcomputador, o jovem estudante estaria sendo introduzido a uma forma radicalmente nova de conhecimento, inacessível à geração de seus pais, educada se tanto no cuspe e no giz. Hoje se sabe que o ensino de linguagens de programação pouco acrescenta a não ser aos especialistas, e a principal contribuição dos computadores é a de expandir e consolidar as habilidades básicas adquiridas na educaçáo convencional, ou seja, a escrita, pelos processadores de texto, o cálculo, aprendido com a aritmética e desenvolvido posteriormente com a matemática e as ciências exatas, e a capacidade de recuperar e organizar informaçóes, própria dos processos de incorporaçáo de qualquer corpo de conhecimento.

Mas em que consiste, afinal, esta tal motivação? Como identificála, e como fazế-la surgir onde ainda nāo existe? Como fazê-la aflorar entre estudantès cujo ambiente familiar não a estimula, por professores mal-pagos, eles mesmos pouco educados e trabalhando em condições freqüentemente precárias, e desprovidos dos recursos pedagógicos mais básicos?

Esta pergunta tem uma resposta antiga, que tem sido hoje redescoberta e revalorizada em todos os níveis da atividade humana, da política à economia, da religiáo à educação: motivaçáo, criatividade, iniciativa, capacidade de aprendizagem, todas estas coisas ocorrem no nível dos indivíduos e das comunidades de dimensóes humanas nos quais eles vivem seu dia-a-dia. Esta seria uma proposiçăo extremamente conservadora 100 ou 200 anos atrás, quando as comunidades locais iam sendo varridas pela criação de grandes estados nacionais, ao passo que a industrializaçáo massificava os indivíduos $\mathrm{e}$, pouco a pouco, pulverizava sua capacidade criativa na divisáo em migalhas da produção em série. $O$ que dá nova vida a esta proposição é a combinação de dois fenômenos concomitantes, o da crise generalizada dos grandes sistemas hierárquicos e verticais de controle, administração e produção social econômica, e a nova flexibilidade e diversificaçáo trazida pelo avanço das novas tecnologias de comunicação de massas, processamento da informaçáo e de produçáo. Em um primeiro momento, estas novas tecnologias pareciam apontar no sentido da progressiva massificação das sociedades modernas, com o longínquo ano de 1984 representando os olhos de big brother no interior de cada casa, as mentes programadas e condicionadas, tudo a serviço de um grande desígnio totalitário. Passada a data fatídica, o 
que se observa nos países mais adiantados é a coexistência das grandes cadeias nacionais de televisáo por uma infinidade de alternativas locais, que vão do acesso a programas internacionais às televisóes locais e especializadas, ou institucionais; a combinaçáo dos grandes computadores com a difusão e o barateamento dos computadores pessoais, com capacidade de acesso direto aos grandes bancos de dados; a volta da pesquisa científica e tecnológica dos laboratórios industriais e militares para as comunidades acadêmicas e universitárias; e a substituiçáo de muitos dos sistemas tradicionais de produção industrial em série por novas formas de produção $\mathrm{em}$ equipe, com forte recuperação dos conteúdos técnicos e cognitivos do trabalho. $O$ que presenciamos hoje, em síntese, não é o predomínio crescente e absoluto das grandes estruturas de informaçáo, administraçáo e poder, nem sua substituiçáo por uma volta à comunidade perdida, mas a criação de um tipo de sociedade extremamente complexa, onde os custos da comunicação e da informaçáo se aproximam cada vez mais a zero, e onde as distinções antigas entre o local, o nacional e o internacional, o pequeno e o grande, o centralizado e o descentralizado, tendem o tempo todo a se confundir, desaparecer. e reaparecer sob novas formas.

De tudo isto, países como o Brasil ficaram, principalmente, com a carcaça das burocracias centralizadas, que foram perdendo progressivamente sua razáo de ser e passaram, cada vez mais, a cuidar com exclusividade de sua própria sobrevivência. Em nenhum setor esta realidade é mais dramática, talvez, do que na área da educação básica, em que burocracias de dezenas e até centenas de milhares de pessoas desempenham suas funçóes de forma geralmente ritualística e rotinizada, sob o comando de administraçóes centrais incapazes de saber e influenciar o que ocorre onde a relação pedagógica realmente se dá, ou seja, nas salas de aula. Devolver a capacidade de iniciativa e inovaçáo às escolas, colocar as pessoas mais capazes e motivadas em contato direto com os alunos, liberar as escolas para buscar os recursos humanos, materiais e motivacionais nas comunidades que as cercam, e recriar, assim, o ambiente de estímulo e motivação indispensável para o trabalho educativo, eis a agenda fundamental de qualquer tentativa de reintroduzir a modernidade em nossa educação básica.

É uma agenda sujeita a fáceis equívocos e confusóes. Primeiro, em relaçăo à tradicional polêmica entre ensino público e ensino privado. Náo se trata de proclamar, também aqui, o fracasso da administração pública, e defender por isto a privatização do ensino. A educaçăo básica é responsabilidade coletiva, e deve receber, em qualquer sociedade, uma parte substancial dos recursos públicos. Público não quer dizer, porém, hierarquizado, uniforme, monolítico e burocrático. A função do Estado, 
em todos os níveis, é a de proporcionar recursos, fixar metas, acompanhar resultados, e corrigir desigualdades e iniqüidades. Isto se faz pelo estabelecimento de padróes de desempenho, acompanhamento de resultados, estabelecimento de incentivos, prestaçăo de serviços de intercâmbio e assistência. A perestroika educacional de que o Brasil necessita consiste em devolver às escolas a autoridade, a responsabilidade, os benefícios e os eventuais custos de seu desempenho.

Segundo, em relaçáo ao tema do relacionamento das escolas com suas comunidades. É muito comum, nos meios educacionais brasileiros, a noção de que as escolas públicas devem ser preservadas de interferências externas, como forma de garantir sua independência $e$ a universalidade de sua tarefa educativa. A realidade, no entanto, é que, por mais que o Estado possa alimentar a escola com recursos e materiais didáticos, nenhuma pode dispensar, sem grandes perdas, o envolvimento da comunidade circundante em suas atividades quotidianas. Este envolvimento vai desde a ajuda material concreta, na forma de contribuiçóes financeiras voluntárias, participaçáo em trabalhos de mutirăo, doaçôes e patrocínios de iniciativas educacionais, até o envolvimento direto dos pais no processo quotidiano de educação de seus filhos. Esta função de apoio familiar à atividade da escola é, sabe-se hoje, o fator mais decisivo para garantir o sucesso da atividade pedagógica que a escola desempenha. Quando, por razóes sociais e econômicas, as famílias dos alunos não lhes dáo este apoio, a tarefa das escolas se amplia: não se trata mais, agora, de simplesmente retirar a criança de um meio supostamente hostil e substituí-lo por um outro ambiente mais adequado dentro da escola, mas, ao contrário, de desempenhar uma tarefa pedagógica que vá além da criança, e envolva, também, a comunidade à qual ela pertence. Este tipo de trabalho é, possivelmente, muito mais do que escolas públicas convencionais, ligadas a secretarias de Educaçáo estaduais, poderiam pensar em desenvolver. Mas ninguém disse que só pode haver escolas públicas deste tipo. Elas podem, também, ser mantidas e geridas por sindicatos, associaçóes de bairros, comunidades religiosas, cooperativas agrícolas, partidos políticos, prefeituras, escolas de samba, times de futebol, e quaisquer outras instituiçōes que existam para unir e congregar as pessoas em todas as partes.

Terceiro, em relação aos processos pedagógicos que presumivelmente facilitem o desenvolvimento da motivação e do interesse pelo aprendizado. É preciso não confundir a questáo mais ampla do estímulo ao interesse e da motivaçáo pela atividade educativa, por parte de alunos, professores e familiares, com determinadas teorias pedagógicas baseadas nos princípios da espontaneidade, do não-direcionamento, $\mathbf{e ~ d a ~}$ criatividade e curiosidade naturais das crianças. Estas teorias se desen- 
volveram, em grande parte, como respostas ao ritualismo, burocratização e repressão, que caracterizavam muitos sistemas educacionais convencionais, que transformavam o processo educativo $\mathrm{em}$ um penoso ritual de iniciaçáo da criança à submissáo à autoridade do adulto. Sem entrar na discussão especializada que este tema requer, é necessário notar, no entanto, que muitas vezes estas pedagogias liberais e antiautoritárias levaram ao completo abandono da atividade pedagógica enquanto tal, com graves prejuízos para as crianças; enquanto isto, metodologias tradicionais, quando aplicadas em ambientes preservados e motivados, podem conduzir a resultados bastante satisfatórios. Este fato tem levado, inclusive, a uma recente revalorizaçáo das pedagogias mais tradicionais e repressivas, um tipo de conclusão que não é, de nenhuma forma, evidente. $O$ que parece ser certo é que, assim como existem muitas maneiras de tosquiar um carneiro, existem, também, maneiras distintas e igualmente satisfatórias de educar uma criança.

Finalmente, a questão dos conteúdos. A escola moderna deve ser, acima de tudo, preparação para a vida num mundo em constante mudança, onde o que conta mais é a capacidade de entender o que ocorre ao redor de si e de crescer continuamente, e não a aquisição de uma habilidade técnica qualquer que se torna obsoleta de uma hora para a outra. Em sociedades integradas e globalizadas como as de hoje, năo faz' sentido transmitir, pela via da escola, um conjunto compartimentalizado e enlatado de conhecimentos que se chocam, ou não se relacionam, com a realidade que entra diariamente pelos olhos e ouvidos das crianças, na televisáo, no rádio, nas conversas em casa, nos jornais. E no entanto, esta realidade quotidiana é fugidia, não guarda sentido de história e tradiçăo, e se alimenta da visibilidade de eventos ocasionais e espetaculares, sem o entendimento de suas características mais permanentes ou profundas. O desafio da educaçáo formal é, sobretudo, o de transmitir estes conteúdos mais permanentes, o conhecimento histórico e a localizaçáo espacial e política de dá sentido e continuidade ao fluir do dia-a-dia em uma sociedade de massas. $O$ primeiro passo nesta tarefa, naturalmente, é introduzir o estudante nos primeiros fundamentos das duas culturas em que o conhecimento humano tem se dividido, a literária - ler, escrever - e a matemática - contar. O leque que se abre, depois, é imenso, e não pode ser resolvido com receitas prévias, currículos mínimos ou livros didáticos. O que o aluno deve receber na escola são as informaçôes, os conhecimentos e as habilidades que fazem parte da tradição cultural de seu meio, e que os professores, como parte viva de sua sociedade, devem naturalmente portar.

Se os professores não portarem estes conhecimentos e esta cultura viva, tudo o que fizerem com seus alunos estará perdido. É possível que 
o próprio conceito de professor, como aquela pessoa formada pelas licenciaturas universitárias, cursos de pedagogia e escolas normais, já esteja se tornando tăo obsoleto quanto o da professorinha normalista que ainda povoa muitas de nossas fantasias pedagógicas. A artificialidade dos cursos de pedagogia que sáo hoje requeridos pelos cursos de licenciatura tanto quanto a falência dos antigos cursos normais sáo evidências claras disto. É provável que, no futuro, a formação pedagógica de nível superior tenda a se concentrar cada vez mais na formaçáo do professor ou professora de jardim-de-infância e das primeiras letras, que introduzem as crianças ao mundo do estudo e da educação, deixando as disciplinas especializadas para outros tipos de profissionais. É uma discussão urgente, que mal começou a ser feita entre nós. De qualquer forma, não resta dúvida que devolver aos mestres o sentido de missão, a vontade de ensinar, a capacidade de inovar, de criar e de buscar seus caminhos, e o reconhecimento devido pelo seu papel, eis, em uma frase, a grande agenda da modernidade para a educaçáo básica, que nos cabe instaurar.

\section{Notas}

1 A crítica aos supostos ingênuos do cientificismo, principalmente nas ciências sociais e humanas, realizadas pela sociologia do conhecimento nas últimas décadas, e que tem como principal referência o texto clássico de Thomas Kuhn sobre as revoluçóes cientuficas, sugere que as construçóes intelectuais, cientificas e técnicas têm um caráter muito mais complicado, contingente e precário do que a palavra objetividade pretendia significar; mas isto não justifica, de forma alguma, sua substituiçāo pela intuição estética ou pelo irracionalismo puro e simples.

2 Para um sumário crítico dos efeitos das propostas pós-modernistas no contexto brasileiro, veja Sérgio Paulo Rouanet, "A verdade e a ilusão do pós-moderno" em As Razbes do Iluminismo, São Paulo, Companhia das Letras, 1987, pp. 229-277.

3 A expressäo foi retirada do Manifesto Comunista. Veja Marshall Berman, All That is Solid Melts Into Air - The Experionce of Modornity. New York, Simon and Schuster, 1982 (há tradução brasileira). A frase de Marx antecipa em mais de um steculo a criftica pós-modernista à crença ingênua nos benefícios da industrialização e da modernização.

4 As aspas se justificam porque, na realidade, as ciências sociais nunca adotaram completamente os pressupostos cientificistas e evolucionistas mais extremados, podendo ser, na realidade, interpretadas principalmente como uma reaçăo a eles. A principal evidência disto é a centralidade de Max Weber nas ciências sociais contemporâneas, em uma interpretação que dá ênfase à sua dimensão histórico-comparativa e "compreensiva", no lugar da leitura formal e sistêmica difundida na literatura de língua inglesa a partir das reinterpretaçöes de Talcott Parsons.

5 Este processo ocorreu até mesmo no ensino superior, onde o charme da pesquisa tecnológica acabou por ofuscar o prestígio de tarefas consideradas menos nobres ou menos úteis, como o ensino profissional $\mathrm{e}$, com maior intensidade, a formação de professores para o ensino básico e médio.

$6 \mathrm{Um}$ raciocínio semelhante se aplica à propaganda, que encontra seus limites quando o produto que busca vender se choca ou contradiz as experiências, motivaçóes e interesses de seu público. 


\title{
Resumo
}

O trabalho discure os conceitos de modernidade e poss-modernidade, e rejeita a idéia de que a agenda da modernidade, ligada à idéia de progresso, educaçăo e desenvolvimento cientúfico, tenha se esgotado. O Brasil ainda tem um projeto de modernização a cumprir, que encontra na educaçăo básica seu aspecto central. Este projeto depende de um novo entendimento de como a questão educacional deve ser equacionada, a partir de uma revisão de temas como o papel do setor público, da relação entre escola e comunidades, os procedimentos pedagógicos $\mathrm{e}$ as questóes de conteúdo, que o trabalho discute.

\begin{abstract}
This article discusses the concepts of "modernity" and "post-modernity", and rejects the notion that the agenda of modernity, linked to the notions of progress, education and scientific development, is exhausted. Brazil still has a modernization agenda to fulfill, which depends on its ability to solve the problems of basic education of its population. To do this, a fresh understanding of how to approach basic education is needed, requiring a new approach to traditional questions such as the role of the public and private sectors, the links between schools and the communities, pedagogical methods and questions of content, which are discussed in the text.
\end{abstract}

Simon Schwartzonan é pesquisador do Centro de Pesquisa e Documentaçáo em História Contemporânea do Brasil da Fundação Getúlio Vargas e membro da Area de Política Científica e Tecnológica do IEA.

Palestra preparada para o "Seminário Nacional de Literatura, Educação e Pós-Modernidade" , organizado pelo Centro de Pesquisas Literárias do Curso de Pós-Graduaçāo em Lingüística e Letras da Pontificia Universidade Católica do Rio Grande do Sul, 24 de junho, 1988 (segunda versão, 8/6/88). 